\title{
Living in the Extreme: Economics of Pandemics, Climate Change and Tail Risks
}

\author{
Emine Boz ${ }^{1} \cdot$ Linda Tesar ${ }^{2}$ \\ Published online: 25 January 2022 \\ (c) International Monetary Fund 2022
}

Extreme events pose enormous challenges to the global economy, as evidenced by the ongoing COVID-19 pandemic and the increased frequency of disasters due to climate change. During such events, historical patterns and conventional approaches become obsolete. Decisions need to be made with limited information about the facts on the ground and with far-from-accurate forecasts about the future. When extreme events are global, there is diminished scope for international risk sharing, and pressures on government institutions, domestic and international, become acute. In the face of these challenges, the 21st Jacques Polak Annual Research Conference of the IMF focused on "Living in the Extreme: Economics of Pandemics, Climate Change and Tail Risks." The conference brought together researchers and policymakers in a virtual setting to discuss innovative research in this area and facilitate the exchange of views on November 5-6, 2020.

In her Mundell-Fleming Lecture, Carmen Reinhart (World Bank Group) discusses the multifaceted economic and financial vulnerabilities created and exacerbated by the COVID-19 pandemic on a foundation of already weak economic fundamentals in many countries. She argues that crises often do not travel alone and that banking, sovereign debt, exchange rate crashes, sudden stops and inflation often intersect to become severe conglomerate crises. Historically, whether of the individual or conglomerate variety, crises influence the shape and speed of economic recovery. As the health crisis morphs into a financial or debt crisis in some countries, Ms. Reinhart discusses what may lie ahead in terms of the stages in crisis resolution and provides a brief reflection on how the resolution process can be expedited.

Steven J. Davis (University of Chicago Booth School of Business), Dingqian Liu (American University) and Xuguang Simon Sheng (American University) examine the financial market implications of the COVID-19 pandemic. They find that stock prices and workplace mobility trace out striking clockwise paths in daily data from mid-February to late May 2020. ("Stock Prices and Economic Activity in the Time

\footnotetext{
Emine Boz

EBoz@imf.org

1 International Monetary Fund, Washington, DC, USA

2 University of Michigan, Ann Arbor, MI, USA
} 
of Coronavirus") The authors show that global stock prices fell 30 percent from 17 February to 12 March, before mobility declined. Over the next 11 days, stocks fell another 10 percentage points as mobility dropped 40 percent. From 23 March to 9 April, stocks recovered half their losses and mobility fell further. From 9 April to late May, both stocks and mobility rose modestly. This dynamic plays out across the 35 countries in the sample, with notable departures in China, South Korea and Taiwan. The size of the global stock market crash in reaction to the pandemic is many times larger than a standard asset-pricing model implies. Looking more closely at the world's two largest economies, the pandemic had greater effects on stock market levels and volatilities in the USA than in China even before it became evident that early US containment efforts would flounder. Newspaper-based narrative evidence confirms the dominant-and historically unprecedented-role of pandemic-related developments in the stock market behavior of both countries.

Moving on to the heterogeneous effects of the COVID-19 pandemic on different segments of the population, Martin Eichenbaum (Northwestern University and NBER), Sergio Rebelo (Northwestern University, NBER and CEPR) and Mathias Trabandt (Goethe University) argue that the epidemic disproportionately affected the economic well-being and health of the poor. ("Inequality in Life and Death") To disentangle the forces that generated this outcome, the authors construct a model that is consistent with the heterogeneous impact of the Covid recession on those with low and with high income. According to their model, two thirds of the inequality in Covid deaths reflect pre-existing inequality in comorbidity rates and access to quality health care. The remaining third stems from the fact that those with low income tend to work in occupations where the risk of infection is high. The model also implies that the rise in income inequality generated by the Covid epidemic reflects the nature of the goods produced by those with low income. Finally, the authors assess the health-income trade-offs associated with fiscal transfers to the poor and mandatory containment policies.

In "Mobility Under the COVID-19 Pandemic: Asymmetric Effects Across Gender and Age," Francesca Caselli, Francesco Grigoli, Damiano Sandri and Antonio Spilimbergo (all IMF) find that overall mobility declined during the COVID-19 pandemic because of government lockdowns and voluntary social distancing. Yet, aggregate data mask important differences across segments of the population. Using unique mobility indicators based on data provided by Vodafone for Italy, Portugal and Spain, the authors find that lockdowns had a larger impact on the mobility of women and younger cohorts. Younger people also exhibited a sharper drop in mobility in response to rising COVID-19 infections. Their findings, which are consistent across estimation methods and robust to a variety of tests, warn of a possible widening of gender and inter-generational inequality.

In the final paper of this issue, Bomin Jiang (MIT), Daniel Rigobon (Princeton University) and Roberto Rigobon (MIT and NBER) study the vulnerabilities of the supply chain to COVID-19. "From Just-in-Time, to Just-in-Case, to Just-in-WorstCase: Simple Models of a Global Supply Chain under Uncertain Aggregate Shocks" poses the question: What does it mean for a supply chain to be robust? The authors develop a stylized model of a supply chain and study how the decision of a multinational corporation changes in the presence of uncertainty. The two standard theories 
of supply chain management are just-in-time and just-in-case. Just-in-time argues in favor of pursuing efficiency, while just-in-case studies how such decision changes when the firm faces idiosyncratic risk. Just-in-worst strategies emerge in the presence of systemic shocks, in which firms concentrate on the outcomes in the worstcase scenario and survival becomes the overriding objective. The authors show that this strategy implies a supply chain where the allocation of resources and capabilities follow a heuristic behavioral rule called "probability matching," a strategy found in nature and in experimental research when subjects are concerned about survival. The authors find that a robust supply chain will reproduce this behavioral outcome. In fact, a multinational optimizing under uncertainty follows a probability matching, which leads to an allocation that is suboptimal from the individual producer point of view but rules out the possibility of supply disruptions.

We think this issue covers a wide range of important questions about the impact of extreme events, including COVID-19, across countries and across individuals, in financial markets as well as production networks and mobility decisions. We thank all the authors for their valuable contributions to this issue and hope that you will enjoy reading it.

Publisher's Note Springer Nature remains neutral with regard to jurisdictional claims in published maps and institutional affiliations.

Emine Boz is an Assistant to the Director at the Research Department of the IMF and a Co-Editor of the IMF Economic Review. She holds a Ph.D. from the University of Maryland and has been at the IMF since 2006. Her work has mainly focused on international macroeconomics and trade. She has published in several leading academic journals including the American Economic Review, Journal of Monetary Economics and the Journal of International Economies.

Linda Tesar is a Professor of Economics in the Department of Economics at the University of Michigan. She served as Department Chair from 2007 to 2011. Professor Tesar is a Research Associate at the National Bureau of Economic Research and has been a visiting scholar in the Research Departments of the International Monetary Fund, the Board of Governors, and the Federal Reserve Bank in Minneapolis. During 2014-15, Professor Tesar served as a Senior Economist on the Council of Economic Advisers. She is currently a member of the AdvisoryBoard of the Carnegie-NYU-Rochester Conference on Public Policy. Professor Tesar's research focuses on issues in international finance, with particular interests in the international transmission of business cycles and fiscal policy, the benefits of global risk sharing, global capital flows, the impact of exchange rate exposure, international tax competition and the European crisis. 